\title{
O ITINERÁRIO DE UM ATLETA OLÍMPICO NÃO MEDALHISTA: WILLY SEEWALD $(* 1900+1929)$
}

\author{
Janice Zarpellon Mazo' \\ Carolina Fernandes Da Silva ${ }^{2}$ \\ Anderson da Cunha Baia ${ }^{3}$
}

\section{RESUMO}

A presente pesquisa busca investigar o percurso esportivo olímpico do atleta brasileiro Willy Seewald, desde o período em que começou a praticar esportes, transcorrendo pela sua participação nos Jogos Olímpicos de 1924, até o encerramento de sua carreira esportiva no final da década de 1920. Para a realização deste estudo, foram utilizadas entrevistas, jornais, revistas e documentos de acervo pessoal da família Seewald. As informações extraídas, e interpretadas por análise documental, revelam que Willy Seewald, além de praticar um leque diversificado de esportes, obteve elevado desempenho na modalidade olímpica lançamento de dardo, bem como demonstrou, que os valores olímpicos estavam incorporados na sua conduta esportiva.

Palavras-chave: História do Esporte. Atletismo. Jogos Olímpicos. Lançamento de Dardo.

1 Doutora em Ciências do Desporto. Professora da Escola de Educação Física, Fisioterapia e Dança da Universidade Federal do Rio Grande do Sul (ESEFID/UFRGS). Porto Alegre/Rio Grande do Sul, Brasil.

E-mail: janice.mazo@ufrgs.br

2 Pós-Doutora em Ciências do Movimento Humano. Professora da Universidade Federal de Santa Catarina (UFSC). Florianópolis/Santa Catarina. Brasil. E-mail: carol_ed.fis@hotmail.com

3 Doutor em Educação. Professor da Universidade Federal de Viçosa (UFV). Viçosa/Minas Gerais, Brasil.

E-mail: anderson.baia@yahoo.com.br 
THE ITINERARY OF A NON-MEDAL OLYMPIC ATHLETE: WILLY SEEWALD (*1900 +1929)

\section{ABSTRACT}

This research investigates the Willy Seewald Olympic sports journey, since the time he started playing sports, through their participation in the Olympic Games in 1924, until the end of his sporting career in the late 1920s. The sources used in this study were interviews, newspapers, magazines, official documents and Seewald family personnel collection. The information extracted and interpreted by document analysis, revealed that Willy Seewald, in addition to practicing a wide range of sports, achieved high performance in Olympic sport Javelin Throw and has shown by his conduct that the Olympic values were incorporated in his sport behavior.

Keywords: History of Sport. Athletics. Olympic Games. Javelin Throw.

\section{EL ITINERARIO DE UN ATLETA OLÍMPICO NO MEDALLISTA: WILLY SEEWALD (*1900 +1929)}

\section{RESUMEN}

Este estudio investiga la ruta deporte olímpico Willy Seewald, desde el momento en que empezó a jugar el deporte, a través de su participación en los Juegos Olímpicos de 1924 hasta el final de su carrera deportiva a finales de 1920 para la realización este estudio, se utilizaron entrevistas y diarios, revistas, documentos y personal de la colección de la familia Seewald oficiales. La información extraída e interpretado por el análisis de documentos, reveló que Willy Seewald, además de practicar una amplia gama de deportes, logra un alto rendimiento en el deporte olímpico de Jabalina, y se ha demostrado con su conducta, que los valores olímpicos se incorporaron en su conducta deportiva.

Palabras clave: Historia del Deporte. Atletismo. Juegos Olímpicos. Jabalina. 


\section{INTRODUÇÃO'}

Os Jogos Olímpicos da Era Moderna (JO) tornaram-se um grandioso evento durante o desenrolar do século XX. Diversas representações deste evento foram compostas e recompostas ao longo do tempo (PRONI, 2008), no entanto, buscou-se perpetuar as principais ideias do fundador dos JO, o Barão Pierre de Coubertin. Tais ideias estavam inseridas na concepção filosófica do Olimpismo, a qual se propõe a criar um estilo de vida baseado na alegria do esforço, no valor educativo do bom exemplo e no respeito pelos princípios éticos fundamentais universais, como consta na Carta Olímpica (IOC, 2016).

De acordo com Müller e Todt (2016), os valores de Pierre de Coubertin se perpetuaram no Olimpismo para além da morte de seu idealizador no ano de 1937. Até os dias atuais há fragmentos do Olimpismo propagados pelo Comitê Olímpico Internacional (COI), que busca pelo esporte disseminar princípios morais e valores. A concepção de atleta olímpico da Era Moderna abarca, dentre outros aspectos, o destacado desempenho esportivo e a conduta moral. Assim, os atletas olímpicos, além de terem que alcançar altos índices de rendimento esportivo para compor o seleto grupo que compete nos Jogos Olímpicos (JO), devem seguir princípios morais estabelecidos, os quais vão ao encontro da filosofia do Olimpismo.

O brasileiro Willy Richard Franz Seewald tornou-se um atleta olímpico, pois participou dos Jogos Olímpicos de 1924, em Paris (França) e sua conduta esportiva era atravessada pelos valores que a Carta Olímpica (IOC, 2016) determinava como essenciais para a construção do indivíduo: a amizade, a excelência e o respeito. No período em que Willy Seewald participou dos JO, edição de 1924, o evento ainda estava muito impregnado do ideal de Pierre de Coubertin: "antes de tudo é necessário que mantenhamos no desporto as características de nobreza e cavalheirismo do passado" (RAMOS, 1982, p. 254).

Willy Seewald foi apontado pela imprensa local como "um gigante moral" (ORGAM REPUBLICANO, 1929) denominação que evidencia as características do atleta olímpico no período. Talvez, esta identificação esteja relacionada a formação esportiva na Leopoldenser Turnverein (Sociedade Ginástica São Leopoldo), na cidade de São Leopoldo/RS ${ }^{5}$. Desde jovem, frequentava as sessões de ginástica alemã na referida instituição, como também jogava futebol no Sport Club Nacional. A família Seewald, como muitas outras de ascendência de imigrantes alemães e seus descendentes, nomeadas de teuto-brasileiros ${ }^{6}$, tinha

4 Os autores declaram não haver conflitos de interesses de natureza pessoal, comercial, política, acadêmica ou financeira quanto à publicação do presente artigo.

5 São Leopoldo é considerada o berço da colonização alemã no estado, pois os primeiros alemães que chegaram ao Rio Grande do Sul foram encaminhados para esta região, em 1824 (SEYFERTH, 1994). Nesta localidade foi criada a segunda associação de ginástica do estado: a Leopoldenser Turnverein (Sociedade Ginástica de São Leopoldo), fundada por imigrantes e descendentes de alemães no dia primeiro de setembro de 1885, após uma tentativa sem sucesso em 1880 (RAMOS, 2000).

6 A expressão "teuto" refere-se à nacionalidade pela retórica de sangue comum, o jus-sanguinis, sendo alemão todo aquele que tem sangue alemão. Enquanto que o termo "brasileiro" estava associado à cidadania, pela concepção do jus-soli. Segundo Seyferth (1992), este termo é utilizado para designar os imigrantes e descendentes de alemães no Brasil. 
na Leopoldenser Turnverein um local de sociabilidade, onde participavam de atividades sociais, culturais e esportivas.

Com relação às práticas esportivas, a Sociedade Ginástica, nas primeiras décadas, oferecia a ginástica alemã ${ }^{7}$ aos associados e, posteriormente, o atletismo. Willy, assim como seus irmãos, frequentava as sessões de ginástica para, mais tarde, começar a praticar o atletismo (MAZO; MADURO, 2009; MIGOTTO, 2012). A ginástica alemã se baseava na crença do uso do exercício físico como instrumento para a educação moral. De tal modo, Willy em seus treinamentos no Leopoldenser Turnverein já incorporava princípios morais sustentados neste método ginástico (MAZO; FROSI; MADURO, 2012).

Willy praticou ginástica alemã e futebol, mas foi no atletismo que ele prosseguiu para o seu melhor desempenho, em particular na modalidade de lançamento de dardo, na qual ele conquistou importantes resultados nas competições estaduais e no cenário esportivo nacional. Em razão disso, foi convidado a integrar o grupo de atletas que representariam o Brasil nos Jogos Olímpicos de 1924, em Paris. Cabe ressaltar que ele foi o único atleta sul-rio-grandense que fez parte deste pequeno grupo, sendo todos os demais oriundos dos estados de São Paulo e Rio de Janeiro.

A presente pesquisa histórica trata de investigar o percurso esportivo de Willy Seewald, desde o período em que começou a praticar esportes, sucedendo sua participação nos JO de 1924 até o encerramento de sua carreira esportiva no final da década de 1920.

A fim de contemplar o objetivo proposto foram realizadas entrevistas alicerçadas nos pressupostos teórico-metodológicos da História Oral (ALBERTI, 2004) com o único irmão vivo de Willy na época da pesquisa, o senhor Erich Seewald, e com sua filha Simone Seewald Albrecht, sobrinha de Willy ${ }^{8}$. Além disso, procedeu-se a uma análise documental das seguintes fontes: reportagens de jornais, revistas, almanaques esportivos, site da CBAt ${ }^{9}$, carta, diploma e medalha de participação nos JO de 1924, medalhas de competições regionais, brasileiras e sul-americanas ${ }^{10}$. Tanto as informações coletadas em distintas fontes, quanto às fontes orais produzidas por meio das entrevistas foram submetidas à análise documental (BACELLAR, 2010) e contrastadas com a revisão bibliográfica sobre o assunto.

Esta pesquisa justifica-se não apenas pelo acesso a uma variedade de fontes sobre o tema ${ }^{11}$, mas, sobretudo, porque o atleta sul-rio-grandense é uma exceção na tendência das

7 A ginástica alemã foi estabelecida no Brasil com um forte apelo nacionalista. Tal ideário nacionalista foi construído na Alemanha ao longo do século XIX e trazido para o país na bagagem cultural dos imigrantes. Segundo Soares (2002, p. 53), "era preciso, portanto, criar um forte espírito nacionalista para atingir a unidade, a qual seria conseguida com homens e mulheres fortes, robustos e saudáveis".

8 Os entrevistados assinaram o Termo de Consentimento Livre e Esclarecido autorizando a publicação de seus nomes na pesquisa, bem como a utilização das informações gravadas e transcritas.

9 Agradecemos ao jornalista Bene Turco da CBAT pelos livros e informações enviadas sobre o tema.

10 Agradecemos a Simone Seewald Albrecht, pelo empréstimo do acervo pessoal de seu tio Willy, bem como pela disponibilidade em esclarecer dúvidas sobre fatos relativos a família Seewald.

11 Nos estudos históricos, a diversidade de fontes colabora para construção da teia de significados impressos nos acontecimentos, o que permite a reconstrução dos fatos e o preenchimento de lacunas de tempo, facilitando a construção da narrativa. Nesse caminho, a pesquisa sobre o atleta Willy Seewald começou no ano 2000, quando produzimos as primeiras fontes orais sobre o atleta, e foi publicado quase 10 anos depois (MAZO; 
delegações olímpicas brasileiras de contarem majoritariamente com atletas da região Sudeste do país. Além disso, se considera significativo abordar, por meio do percurso de um atleta, a oitava edição do ciclo olímpico, na qual identificamos pela segunda vez, a participação de atletas brasileiros. Desde a primeira participação de atletas brasileiros em JO, edição de 1920 na Antuérpia (Bélgica), a caminhada de muitos deles, como ocorre nos dias atuais, é calcada por obstáculos os quais são superados, muitas vezes, pelo esforço individual e apoio de familiares. No caso dos atletas pioneiros, como Willy Seewald, tão maiores foram os obstáculos enfrentados, visto que nas primeiras décadas do século XX, o esporte no Brasil não era foco de políticas públicas governamentais e esta situação era um dos empecilhos para atletas que almejavam conquistas nas competições esportivas. Apesar desta conjuntura, os percursos dos atletas são também marcados por momentos de glórias, mesmo quando não conquistavam um lugar no pódio, como ocorreu no caso de Willy Seewald.

\section{WILLY SEEWALD E OS ESPORTES}

Desde a infância, Willy e seus irmãos tiveram a oportunidade da prática esportiva. Como a propriedade onde residia, atual cidade de São Leopoldo, ficava junto às margens do Rio dos Sinos, Willy e seus irmãos encontraram o ambiente propício para desenvolverem as práticas da natação e do remo. Todavia, eles não se limitaram apenas a estes esportes e foram buscar novas práticas e espaços esportivos.

Willy, seguindo os passos do irmão Erich, aos oito anos de idade começou a frequentar o Clube Esportivo Nacional de São Leopoldo e, posteriormente, participar de sessões de Turnen (ginástica alemã) na Leopoldenser Turnverein, à noite. Erich, desde os 16 anos de idade, jogava futebol no referido clube e fazia ginástica alemã, denominada por ele, em entrevista, de ginástica de aparelhos (argola, barra, cavalo com alças, paralela e solo) na sociedade de ginástica. As aulas de ginástica, naquele período, também compreendiam a corrida, o arremesso e o salto, os quais eram realizados de variadas formas e "constituíam, com suas práticas, verdadeira escola de atletismo" (RAMOS, 1982, p. 188).

A Leopoldenser Turnverein foi uma das promotoras do atletismo no estado do Rio Grande do Sul, porém os clubes pioneiros foram a Turnerbund ${ }^{12}$, a Associação Cristã de

MADURO, 2009). Entretanto, foram encontradas novas fontes impressas sobre o assunto, possibilitando não apenas o aprofundamento da pesquisa, mas a construção de nova versão sobre a vida esportiva do atleta (MAZO; FROSI; MADURO, 2012). Este artigo (2012) serviu de referência para a produção do documentário “O Admirável Lançador de Dardos" (MIGOTTO, 2012), disponível em: https://www.youtube.com/watch?v=jypdiYhgG_0. A participação da professora Janice Mazo neste documentário desencadeou dúvidas a respeito de situações da vida esportiva de Willy Seewald. E, na busca de respostas para algumas questões, fomos revisitar as fontes de pesquisa acessadas ao longo de 16 anos de pesquisa, bem como garimpar novas fontes, após quase 90 anos da morte do atleta. Os resultados da nova narrativa sobre o atleta olímpico são apresentados no presente estudo.

12 A Turnerbund, atual "Sociedade Ginástica Porto Alegre, 1867", conhecida como SOGIPA, foi fundada em 1867 pela iniciativa de imigrantes alemães na cidade de Porto Alegre. Esta sociedade foi a segunda instalada no Brasil, após a sociedade de ginástica fundada em Joinville/SC. Depois da fundação da Turnerbund outras sociedades de ginástica foram instaladas em cidades do estado do Rio Grande do Sul com marcante presença de imigrantes alemães e seus descendentes (MAZO e colaboradores, 2012; SILVA, 1997; TESCHE, 1996). 
Moços (ACM) ${ }^{13}$ e o Grêmio Foot-Ball Porto Alegrense (GFPA), todos situados em Porto Alegre $^{14}$. O atletismo era uma prática recomendada à saúde e educação moral dos imigrantes alemães e seus descendentes. As sociedades de ginástica, além de valorizar a cultura alemã e a educação moral da juventude, também promoviam o culto da saúde corporal (KILPP; ASSMANN; MAZO; 2014).

Para além de melhorar a condição física, as práticas também tinham como finalidade "um exercício moral: alcançar autoconfiança, autodisciplina, independência, lealdade, e obediência. Buscava-se atingir essas metas por meio de atividades completas e informais" (PUBLIO, 2005, p. 17), incluindo-se as atividades sociais realizadas nos finais de semana. Assim como para a família Seewald, fazia parte da tradição dos imigrantes alemães e seus descendentes, a prática esportiva, conforme relatou Erich (SEEWALD, 2000, p. 2).

Foi na Sociedade Ginástica de São Leopoldo que Willy conheceu as modalidades do atletismo, quando tinha 18 anos de idade. Praticou salto com vara, salto em altura, arremesso de peso, lançamento de disco e lançamento de dardo. Contudo, manteve a prática do futebol até os 22 anos de idade quando decidiu, provavelmente, em razão dos resultados conquistados em competições locais e regionais, dedicar-se exclusivamente ao atletismo. Não foram localizadas informações sobre os motivos da escolha do lançamento de dardo por Willy. Mas, além de ser apresentado à modalidade na sociedade ginástica, talvez a tradição da família Seewald na fabricação artesanal de obras de arte para as igrejas, móveis, caixões, dentre outros artefatos tenha contribuído para a eleição, em particular, de tal prática esportiva.

O pai de Willy, o imigrante alemão Karl Robert Seewald, nascido na região da Baixa Silésia, chegou ao Rio Grande do Sul no mês de junho de 1896. Quando se casou com a teuto-brasileira Augusta Feistauer Seewald, foram morar em uma casa construída nas imediações do Rio dos Sinos, região de São Leopoldo (MÜLLER, 1986). Ao lado da sua residência ergueu uma fábrica de marcenaria, que a partir de 1916, denominou-se Seewald Troian (mantém-se até os dias atuais). Esta fábrica tornou-se uma referência, pois além da produção artesanal de móveis de arte com alta qualidade, era a única que fazia caixões sob medida para as pessoas falecidas (SEEWALD TROIAN, 03/12/2016).

O casal Seewald teve sete filhos, a saber: Marta Emilia, Affonso, Edgar, Walter, Carlos, Erich e Willy (SEEWALD, 2001; SEEWALD TROIAN, 03/12/2016). Todos trabaIharam junto com o pai, mas parece que Willy Seewald, apelidado de Didi pela família, se destacava no trabalho. Consta que Willy, ao perceber o crescimento nas encomendas de ataúde para agilizar a produção dos caixões, passou a cortar tábuas em tamanhos pré-estabelecidos "e, contra a vontade de seu pai, mantinha um estoque razoável de urnas" (SEEWALD TROIAN, 03/12/2016).

13 A ACM Porto Alegre foi fundada em 1901 e era uma incentivadora da prática do atletismo na cidade de Porto Alegre (BAÍA, 2012; MAZO, SILVA, FROSI, 2012; MAZO e colaboradores, 2012).

14 Nas transições do século XIX para o XX, práticas como os saltos, as corridas, o arremesso e os lançamentos, hoje identificadas como modalidades do atletismo, inseriam-se no campo da ginástica alemã e tinham sua identidade, inclusive, reforçada pelas divulgações nas notas esportivas da imprensa (MAZO; MADURO; PEREIRA, 2010). 
Nesta época, além de trabalhar na fábrica da família, nos momentos de folga Willy praticava lançamentos, ainda não com dardos, mas, sim, com varas de bambu no vasto campo que era propriedade da família. Na juventude, quando aprendeu a técnica do lançamento de dardos e deparou-se com a limitação do número de dardos disponíveis para treinar, decidiu fabricar seus próprios equipamentos (SEEWALD, 2001). Na época havia carência de equipamentos esportivos e as instalações da Leopoldenser Turnverein ainda eram limitadas. Os recursos para a manutenção desta sociedade de ginástica provinham dos associados. A compra de um dardo era, assim, dificultada pelo custo e, também, porque não era facilmente encontrado para a venda.

As adversidades motivaram Willy a confeccionar dardos de madeira na fábrica de móveis da família. Willy aprendeu o ofício da marcenaria com seu pai e trabalhava junto com ele e seus irmãos na produção de esculturas em madeira para as igrejas, casas e outros estabelecimentos ${ }^{15}$. Ao experimentar o lançamento de dardo confeccionado com madeira, observou que era superior ao de vara de bambu, o qual vibrava durante o trajeto percorrido. Desde então, passou a produzir dardos utilizando lâminas de madeira coladas juntas, em sentido inverso longitudinal, conservando assim uma perfeita unidade. Segundo depoimento de seu irmão Erich, Willy escolhia um pedaço de madeira especial, como a Guajuvira (cerne) ou a açouta-cavalo, o qual era dividido em três partes, que eram coladas para diminuir a vibração, além de "outros segredos para fazer os dardos que ele não contava" (SEEWALD, 2001, p. 7).

Os dardos confeccionados, artesanalmente, eram testados no campo de futebol do Clube Esportivo Nacional em São Leopoldo. Com o tempo, Willy foi aprimorando a produção "fazendo dardos com três laminas e com perfeito acabamento" (SEEWALD, 2001, p. 7). Com o passar dos anos, os dardos eram encomendados para uso nos clubes e até mesmo unidades militares, além de serem utilizados pelo atleta nas competições.

\section{WILLY TORNA-SE ATLETA OLÍMPICO}

Willy Seewald foi alcunhado em reportagens de jornais da época como o "admirável lançador" (IUGUENFRITZ, 1929, p. 1). Talvez esta denominação deve-se ao reconhecimento do seu desempenho técnico e a obtenção de marcas surpreendentes nas provas de lançamento de dardo nos anos de 1920. No Campeonato Brasileiro de Atletismo do ano de 1921, "superou o recorde nacional por mais de três metros, quando alcançou 44,5m" (CONTRA RELÓGIO, 1997, p. 27).

No ano seguinte, em 1922, Willy Seewald integrou a delegação sul-rio-grandense, composta por oito atletas, que foi disputar o evento esportivo comemorativo ao Centenário da Independência do Brasil (1822-1922), realizado no mês de setembro na capital do país, na época Rio de Janeiro (O IMPARCIAL, 16/09/1922; TORRES, 2006). A competição recebeu diferentes denominações, conforme as fontes consultadas, como, por exemplo,

15 Alguns destes artefatos estão expostos no Museu Visconde de São Leopoldo, em São Leopoldo/RS. 
"Jogos Atléticos", "Jogos Latino-Americanos" (VICARI; MAZO, 2011; VICARI; SILVA, 2014) e "Jogos Olímpicos Latino-Americanos" (TORRES, 2012).

Em sua obra sobre os "Jogos Olímpicos Latino-Americanos", Torres (2012), além de abordar como ocorreu a difusão do ideal olímpico na América Latina, por meio da parceria do Comitê Olímpico Internacional (COI) e da ACM, cita as competições esportivas realizadas no evento. Nas competições de atletismo, Willy Seewald disputou a prova de lançamento de dardo, na qual obteve a marca de 54,515 m (O IMPARCIAL, 16/09/1922). Faz-se a ressalva que de acordo com Gonçalves; Muller (s/d), a marca de Willy foi de $56,885 \mathrm{~m}$. Independente de qual foi a marca, ambos os resultados foram superiores ao do chileno Arturo Medina, que até então era recordista sul-americano com a marca de 50,30 m (O IMPARCIAL, 16/09/1922; CONTRA RELÓGIO, 1997, p. 27).

$\mathrm{O}$ atleta Arturo Medina não se conformou com a derrota e solicitou à comissão de juízes da prova que fizesse a pesagem do dardo utilizado por Willy Seewald, como também avaliasse suas dimensões. Não localizamos informações se a comissão de juízes atendeu ou não a solicitação do atleta chileno, mas tal fato causou um desentendimento com a delegação do Chile, que exigiu a anulação dos resultados de todas as competições de atletismo (TORRES, 2012). Em razão disso, Willy Seewald, no final da competição não recebeu a medalha pela conquista do recorde sul-americano.

Após sua destacada participação nos "Jogos Olímpicos Latino-Americanos", Willy continuou superando índices em competições, mas a grande surpresa foi sua convocação para, junto com atletas majoritariamente oriundos de São Paulo, fazer parte da delegação brasileira composta por apenas onze homens, que disputaria a oitava edição dos Jogos Olímpicos da Era Moderna na cidade de Paris, na França, em 1924. Willy Seewald foi convidado pela Federação Paulista de Atletismo para participar dos JO de 1924, em Paris. Entretanto, segundo seu irmão Erich, o convite ocorreu também pela influência do empresário e esportista paulista Alberto Jackson Byngton (NICOLINI, 2016), que mantinha amizade com a família Seewald (SEEWALD, 2001, p. 12). Inclusive, Erich afirmou que a participação se concretizou devido à ajuda financeira da família Byngton, pois seu pai não tinha recursos suficientes para custear a viagem (SEEWALD, 2001, p. 12). Nicolini (2016) apresenta outra versão sobre a verba que possibilitou a viagem de Willy aos JO, esclarecendo que os recursos financeiros resultaram de uma campanha pública, que contou com a ajuda financeira do empresário e esportista Alberto Byington.

Inicialmente, estava prevista uma ajuda "do governo brasileiro no valor de 350 contos de réis para a preparação e viagem da delegação aos Jogos de Paris" (RUBIO, 2006, p. 105). Contudo, houve a cassação da verba e a remoção oficial da inscrição da delegação brasileira devido aos impasses com a Confederação Brasileira de Desportos (CBD). Consta que os dirigentes esportivos da CBD, cuja sede era no Rio de Janeiro, não tinham muito interesse em participar do evento (NICOLINI, 2016). Diante desta conjuntura, a "Federação Paulista de Atletismo realizou uma campanha visando arrecadar dinheiro, patrocinada pelo jornal 'O Estado de São Paulo', para conseguir a verba necessária para o pagamento das despesas de viagem e alojamento" (RUBIO, 2006, p. 105). Vale a ressalva, que já naquela época, os atletas enfrentavam problemas em razão de conflitos internos das entidades esportivas brasileiras. 
De tal modo, a equipe olímpica brasileira foi composta por atletas de São Paulo, pelo sul-rio-grandense Willy Seewald e dois remadores do Rio de Janeiro ${ }^{16}$. No total, a equipe foi composta por onze pessoas, entre atletas de remo e tiro ao alvo, mais o jornalista Américo Neto, que chefiava a delegação e tinha coordenado a campanha de arrecadação de recursos financeiros. No dia 28 de maio de 1924, a delegação embarcou no navio a vapor Orania, de uma companhia holandesa, para participar dos Jogos Olímpicos.

Os JO de Paris iniciaram no dia três de maio de 1924, contando com 3.089 (ou 3.092) atletas, sendo 136 mulheres, com a participação de 44 países. Grandes nações se ausentaram das competições olímpicas, alegando falta de segurança, devido ao acirrado clima de conflito decorrente da Primeira Guerra Mundial (1914-1918). A Alemanha, a Áustria e a Rússia, na época potências econômicas e esportivas, não enviaram suas delegações para o evento.

Nesta edição dos JO não houve conquista de medalhas pelos atletas brasileiros. Além disso, existe conflito de informações nas fontes quanto à classificação de Willy Seewald na prova de lançamento de dardo. Conforme registro (SONHO E CONQUISTA... 2004) Willy Seewald obteve o nono lugar na primeira eliminatória da prova de lançamento de dardo com a distância de 49,39m. Nicolini (2016) afirma que, com exceção dos atletas cariocas do remo, todos os representantes do Brasil obtiveram resultados acima do $10^{\circ}$ lugar. O livro organizado por Turco (2016) revela que a marca de Willy nos JO ficou longe do que era esperado do atleta.

Em entrevista, Erich, irmão de Willy afirma que ele conquistou o quarto lugar na competição. Willy Seewald, em conversa com seu irmão Erich, comentou que sua marca poderia ser melhor, caso não tivesse adoecido na viagem de navio do Brasil para Paris. No lançamento de dardo, a primeira marca registrada pertence a Adolf Wigert, da Suécia, com $35,81 \mathrm{~m}$ em 1886, e o primeiro recorde da Federação Internacional de Atletismo (IAAF) compete ao seu compatriota Eric Lemming, que em 29 de setembro de 1912, na cidade de Estocolmo, atingiu a marca de $62,32 \mathrm{~m}$. O lançamento de dardo é uma das provas de campo do atletismo que faz parte do programa olímpico moderno desde 1908, mas a participação de um atleta brasileiro nesta prova em um evento internacional ocorreu após 16 anos daquela edição dos JO, somente em 1924, com a participação de Willy Seewald.

Após o encerramento dos JO, Willy Seewald viajou para a cidade de Colônia, na Alemanha, a fim de visitar parentes. Durante sua estadia na cidade, foi convidado para participar de um meeting de atletismo, "no mais Moderno Estadio Europeo para praticas esportivas com possibilidade para as mais diversas modalidades, tendo a capacidade para 80.000 pessôas" (SEEWALD, 1924). Ainda, consta que o atleta fizera um arremesso de dardo com mais de 56 metros no meeting de atletismo. A notícia, também alude que Willy era campeão brasileiro e sul americano de lançamento de dardo. Estas informações foram extraídas de um recorte de jornal da cidade de Colônia, que foi enviado, juntamente com

16 Os irmãos Edmundo e Carlos Castello Branco, com recursos próprios, participaram dos Jogos Olímpicos de 1924, conquistando o quarto lugar na prova de remo doublé sculls, distância de 2.000 metros, com o tempo de 6 min 38 seg. 
uma carta, por Robert Seewald, primo de Willy Seewald, residente na Alemanha. Tanto o recorte de jornal como a carta, foi traduzido do idioma alemão para a língua portuguesa por Erich Seewald (SEEWALD, 2001, p. 15). De fato, alguns teuto-brasileiros mantinham contato por meio de cartas com parentes na Alemanha, como era o caso da família Seewald.

Quando retornou ao Brasil, após o curto período de tempo na Alemanha, Willy Seewald, foi recepcionado em São Leopoldo como um "herói olímpico". De acordo com Rubio (2001), o herói esportivo é construído a partir de um feito exaltado e enaltecido por analogias bélicas. Desta maneira, constrói-se um personagem com características particulares, as quais permitem distingui-lo de outro atleta. Assim, o atleta olímpico se constitui em um processo que ocorre devido a uma edição midiatizada de fatos e acontecimentos que, aliada ao carisma do ídolo, é facilmente recebida pelo público (HELAL, 1999). Tal afirmativa vai ao encontro do depoimento de Marta, tia de Willy, quando relatou que ele chamava a atenção das moças da cidade, as quais tentavam imitar os movimentos dele para executar o lançamento de dardo.

Assim, o artesão da madeira, que vivia no interior do estado do Rio Grande do Sul, foi o único atleta sul-rio-grandense que disputou os Jogos Olímpicos de 1924. Na época, esta competição era terreno dos entusiastas europeus, os quais se distinguiam de homens como o atleta brasileiro, legitimando sua posição social através do discurso do puro esporte e do amadorismo.

O amadorismo, em meados do século XIX, estava vinculado ao imaginário de "uma cultura moralmente mais pura (...) que combinava noções de honra e de esforço" (HOLT; VIGARELLO, 2008, p. 434). Assim, foi incorporado aos ideais olímpicos desde as suas raízes na Era Moderna. Tal acepção de esporte amador afetou o significado do esporte no período, cuja prática "não consistia apenas em obter resultados, em perder ou em ganhar, mas era também portador de germes de desintegração social" (HOLT; VIGARELLO, 2008, p. 434). Esta concepção foi adotada pelo Barão de Coubertin, idealizador do movimento, como a filosofia norteadora dos JO. O amadorismo foi um dos principais elementos que guiaram o esporte olímpico ao longo do século XX.

No período, o amadorismo era uma característica também do esporte brasileiro, por isso, os atletas não cogitavam a possibilidade de receber dinheiro, especialmente aqueles oriundos das sociedades de ginástica, que primavam pelo esporte amador. Willy Seewald teve que superar dificuldades financeiras. Quando viajava para as competições era abrigado em casas de família ou nas instalações dos clubes. Em depoimento, seu irmão Erich lembrou: "não existia alojamento, esse tipo de coisa; às vezes, nós ficávamos acampados em um salão de clube e todos dormiram no chão" (SEEWALD, 2000, p. 3). Os atletas não recebiam qualquer ajuda de custo para participar das competições, de acordo com o depoimento enfático de Erich Seewald: “Não, não, de dinheiro, nunca envolveu dinheiro, de maneira nenhuma" (SEEWALD, 2000, p. 5). Possivelmente, esta afirmação esteja ligada a uma concepção de amadorismo que atravessava o campo esportivo na época, pois ao longo dos anos a acepção de amadorismo se transforma de acordo com o contexto.

De tal modo, Willy Seewald era considerado um sportman, ou seja: "gigante físico, pelos seus músculos de aço, o gigante moral, pela sua educação de adversário correto 
e leal" (IUGUENFRITZ, 1929, p. 1). Importa assinalar que Willy Seewald ultrapassou as fronteiras simbólicas que separavam o "homem simples" do gentleman. E, considerar que naquele período um esportista para ser reconhecido como tal precisava estar vinculado a um determinado ethos, nos mostra mais uma das qualidades de Willy Seewald. Sobre esta forma de distinção social, Guttman (1978, p. 31), ao comentar as restrições elitistas do acesso ao esporte na Europa, lembra que nas regras da Regata de Henley de 1879, se lê "ninguém pode ser considerado remador [...] caso seja ou tenha sido por negócio ou emprego por salário um mecânico, artesão ou operário".

\section{O atleta olímpico prossegue nas competições}

Em São Leopoldo, Willy continuou a treinar e no ano seguinte, em 1925, participou do "I Campeonato Brasileiro de Atletismo", realizado na cidade de São Paulo, vencendo a prova de lançamento de dardo com a marca de $54,11 \mathrm{~m}$. Esta marca foi o primeiro recorde brasileiro reconhecido no lançamento de dardo. Nos dois anos que se seguiram sagrou-se campeão "mantendo o mesmo nível técnico" (DE ROSE, 1949, p. 138). Em 1926, venceu a segunda edição do campeonato brasileiro, alcançando a marca de $56,17 \mathrm{~m}$ e, no ano de 1927, no "III Campeonato Brasileiro de Atletismo" atingiu a marca de 54,90m (CONTRA RELÓGIO, 1997, p. 27).

Willy não participou do "IV Campeonato Brasileiro de Atletismo" no Rio de Janeiro, no mês de setembro de 1928. Não encontramos documentação que elucidasse os motivos da ausência de Willy no evento esportivo. Nesta competição, seu recorde nacional foi superado pelo atleta Joaquim Duque da Silva, que atingiu 57,225 m. Cabe referir que Joaquim Duque da Silva foi campeão na prova de lançamento de dardo no Campeonato Sul-americano de 1931, em Buenos Aires, Argentina (GONÇALVES; MULLER, s/d).

A despeito da marca obtida por Joaquim Duque da Silva, provavelmente, Willy estaria entre os atletas convocados para participar dos JO de 1928, caso o Brasil tivesse enviado uma delegação para participar em Amsterdã (Holanda). No entanto, o Brasil não participou desta edição do evento em razão da crise econômica que o país atravessava, a qual impediu que houvesse recursos suficientes para enviar uma delegação (O IMPARCIAL, 9/09/1928). Mesmo que tenham outros motivos, este fato foi lamentável para Willy que, inesperadamente, faleceu no começo do mês de fevereiro de 1929 (BRENDEMEIR, 2009; IECLB, 15/05/2009; JORNAL UNIÃO..., 1929).

A morte de Willy surpreendeu a todos. Ele estava casado quase há dois anos e morava na cidade de Canoas/RS, quando sentiu fortes dores no abdômen e foi levado com urgência para o Hospital da Beneficência Portuguesa em Porto Alegre. Seu irmão, Erich, contou em depoimento emocionado que no hospital o médico americano Basílio Septor queria fazer a cirurgia: "ele queria abrir, pra ver. Papai disse não. O pai disse: não, agora é tarde" (SEEWALD, 2001, p. 12). Logo em seguida, ainda no hospital, o atleta faleceu em razão de apendicite.

A ausência de Willy foi notada nos eventos esportivos realizados no ano de 1929. O falecimento do atleta foi mencionado na abertura do "VII Torneio de Atletismo", 
promovido pela Liga das Sociedades de Ginástica do Rio Grande do Sul, no estádio da Turnerbund (atual SOGIPA), como também na cerimônia de abertura do " 5 Campeonato Estadual de Atletismo", sob o patrocínio da Liga Atlética Rio-Grandense (LARG). Em ambos os eventos, a cerimônia de abertura foi prestigiada pelo governador do Rio Grande do Sul, Getúlio Vargas e outras autoridades militares (MAZO, 2004).

$\mathrm{O}$ atleta recém-falecido foi também lembrado no "V Campeonato Brasileiro de Atletismo", realizado entre fins de agosto e início de setembro de 1929, na cidade do Rio de Janeiro. Foi aludido na cerimônia de abertura do evento no estádio do Clube de Regatas Vasco da Gama, quando se solicitou aos presentes: "um minuto de lembrança para Willy Seewald" (IUGUENFRITZ, 1929, p. 1). Da mesma forma, uma crônica publicada no suplemento esportivo O Imparcial do Rio de Janeiro, reproduzida pelo jornal de São Leopoldo, cidade natal do atleta, relembrou sua ausência no Campeonato Brasileiro de Atletismo: [...] não podemos deixar esquecido o nome de Willy Seewald, o grande atleta gaúcho que a dois de fevereiro do corrente ano foi arrebatado pela morte (IUGUENFRITZ, 1929, p. 1).

A vida de Willy durou quase o mesmo tempo que seu recorde estadual levou para ser superado. Após 27 anos, o recorde sul-rio-grandense conquistado por Willy foi sobrepujado pelo atleta Nicanor Missaglia, do Grêmio Foot Ball Porto Alegrense, que obteve a marca de 58,2m, no ano de 1949 (CONTRA RELÓGIO, 1997, p. 27).

Willy recebeu muitas medalhas das competições que participou, mas uma não chegou às suas mãos em vida: a medalha da conquista do recorde sul-americano nos "Jogos Olímpicos Latino-Americanos", em 1922. Houve um impasse quanto ao vencedor conforme contou seu irmão (SEEWALD, 2001). No entanto, na semana seguinte ao seu falecimento, a família Seewald recebeu a medalha, um fato que causou grande comoção nos familiares, bem como nos moradores de São Leopoldo, que o distinguiam como herói. Décadas depois, um "lugar de memória" (NORA, 1993) foi fixado nas ruas da cidade para o atleta: Rua Willy Seewald, situada no Bairro Arroio da Manteiga, cujo CEP é 93.135-520.

Após 90 anos da conquista da medalha na prova do lançamento de dardo nos "Jogos Olímpicos Latino-Americanos", 1922, o atleta Willy Seewald foi relembrado no Congresso da Confederação Sul-Americana de Atletismo (Consudatle) em São Paulo realizado antes do início do Campeonato Sul-Americano de Atletismo Sub 23. Os dirigentes da Consudatle revalidaram os resultados obtidos por todos os atletas nas provas de atletismo do evento de 1922, os quais foram anulados na época (LAGUNA, 2012). Curiosamente, Willy não viu sua medalha, como também não presenciou o reconhecimento de sua marca.

\section{CONSIDERAÇÕES FINAIS}

O atleta olímpico Willy Seewald destacou-se no cenário esportivo brasileiro. Para além de ter participado dos Jogos Olímpicos de Paris, em 1924, era, também, reconhecido pela sua grandeza moral, demonstrada na sua disposição constante de agir em uma determinada direção. De acordo com as fontes analisadas, o desempenho deste esportista ultrapassou a pista de lançamento de dardos. Ao longo de sua vida, Willy Seewald 
interiorizou valores, normas e princípios sociais, que asseguram, dessa forma, a adequação entre as ações do sujeito e a realidade objetiva da sociedade como um todo.

Com os irmãos, descobriu as práticas esportivas e seu passado de vivências em diversificado número de esportes transparecia em seus movimentos. Ainda, ao percorrer a trajetória de Willy Seewald, foram encontrados indícios do protagonismo dos imigrantes alemães e seus descendentes no campo esportivo sul-rio-grandense e brasileiro. Em particular, as fontes mostraram que as sociedades de ginástica atuaram de forma decisiva na introdução e difusão de várias práticas esportivas no Rio Grande do Sul e no Brasil. Não apenas na formação de atletas, mas também incentivando a prática esportiva enquanto um dos pilares para a formação físico-esportiva e moral dos cidadãos, onde a ginástica alemã era vinculada à promoção da saúde, à formação moral e à preparação para o trabalho. Ademais, o caso de Willy Seewald revela que ser esportista fazia parte do modo de ser alemão no Brasil, ou seja, de uma identidade teuto-brasileira que se (re) construiu no Brasil nos distintos momentos históricos.

Na sua atividade profissional, Willy exerceu a disciplina e utilizou dos recursos, tanto intelectuais quanto materiais, para aprimorar o seu desempenho esportivo, pois desenvolveu os próprios dardos, a partir de uma análise do material e o melhor formato do instrumento. Com determinação cruzou o oceano para representar o Brasil na França, mesmo que o balançar do barco causasse um desconforto que o abalou fisicamente. Em território Europeu, procurou por seus ascendentes familiares.

Os desafios do caminho percorrido pelo lançador de dardos - de São Leopoldo/ RS a Paris/França - impele um olhar mais aprofundado, especialmente por abordarmos a história de vida de um atleta brasileiro imbricado no contexto histórico-cultural da década de 1920. Em um período no qual não havia políticas esportivas no Brasil, ele foi um atleta que representou o país nos Jogos Olímpicos, evento que estava no seu período de estabelecimento, apesar de já ter uma importância mundial. Destaca-se também a velocidade da ascensão esportiva deste atleta, que em menos de 10 anos conquistou recordes regionais, nacional e sul-americano, demonstrando um desempenho esportivo significativo.

Willy Seewald não trouxe as cobiçadas medalhas de ouro, prata ou bronze dos Jogos de 1924, Paris, mas conquistou a medalha olímpica de participação, a qual simboliza que os valores representados pelos atletas olímpicos - a amizade, o respeito e a excelência -, foram praticados durante a sua participação. Tais representações fazem de Willy um esportista para ser lembrado.

Além disso, Willy contribuiu para a disseminação do atletismo no Rio Grande do Sul, pois seus feitos foram divulgados pela imprensa local, despertando a admiração dos sul-rio-grandenses. Ao mesmo tempo, colaborou para o reconhecimento do estado como um dos polos do atletismo nacional. Foi da iniciativa privada de clubes, bem como por ação de alguns entusiasmados pelo esporte, que praticantes transcenderam da prática cotidiana do atletismo à projeção internacional.

A fim de refletir acerca dos esforços e da trajetória dos precursores do mundo esportivo, buscou-se apresentar neste estudo um dos representantes da saga vivida por muitos esportistas que se lançaram nas primeiras missões olímpicas ao exterior. De certa forma, 
a montagem deste quebra-cabeça que enfocou a memória esportiva brasileira foi limitada. Uma das dificuldades enfrentadas decorre da destruição e extravio de documentos, principalmente em certos períodos históricos do Brasil - Primeira Guerra Mundial (1914-1918); Estado Novo (1937-1945); Segunda Guerra Mundial (1939-1945), em razão do processo de abrasileiramento das sociedades de ginástica fundadas pelos imigrantes alemães nos mencionados períodos da história. Mas, felizmente em um país como o Brasil, cuja preservação da memória esportiva ainda é pouco aclamada até mesmo no meio acadêmico, buscamos apresentar uma versão possível com os vestígios localizados.

\section{REFERÊNCIAS}

ALBRECHT, SIMONE. Simone Seewald Albrecht. (depoimento, 15/5/2009). São Leopoldo, RS.

ALBERTI, Verena. Manual de História Oral. 2a ed. Rio de Janeiro: Editora FGV, 2004.

BAIA, Anderson. Associação Cristã de Moços no Brasil: um projeto de formação moral, intelectual e física (1890-1929). Tese de Doutorado. Faculdade de Educação. Universidade Federal de Minas Gerais, 2012.

BACELLAR, C. Fontes documentais: uso e mau uso dos arquivos. In: PINSKI, Carla (Org.). Fontes históricas. São Paulo: Contexto, 2 ed., 2010, p. 23-80.

BRENDEMEIR, Friedrich. Friedrich Willy Brendemeir. (depoimento, 18/6/2009). São Leopoldo, RS.

CONTRA RELÓGIO, Revista, n. 47, agosto 1997, p. 26-27.

DE ROSE, Tulio. Campeonato de Atletismo. In: AMARO JÚNIOR, José. Almanaque Esportivo do Rio Grande do Sul. Porto Alegre: Tipografia Esperança, 8ª ano, 1949.

GERTZ, Rene. O perigo alemão. Porto Alegre: Editora da UFRGS, 1991.

GONÇALVES, José Clemente; MULLER, Elisabeth Clara. Atletismo Brasileiro. Mimeo, s/d.

GUTTMAN, Allen. From Ritual to Record - the nature of modern sports. New York: Columbia University Press, 1978.

HELAL, Ronaldo. Mídia, ídolos e heróis do futebol. Revista Comunicação, Movimento e Mídia na Educação Física. Santa Maria, RS., vol. 2, ano 2, CEFD/UFSM,1999.

IECLB, Comunidade Evangélica de Confissão Luterana em São Leopoldo. Declaração de falecimento de Willy Richard Franz Seewald. Livro de Registro de Óbitos, volume III, 1863-1941, página 63 sob o nº 05. São Leopoldo, 15/05/2009.

IOC - International Olympic Committee - Disponível em: https://www.google.com.br/ webhp? sourceid $=$ chrome-instant\&ion $=1 \&$ espv $=2 \&$ ie $=$ UTF-8\#q $=$ international + oly mpic + committee + olympic + charter. Acessado em 21 de Junho de 2016.

IUGUENFRITZ, Álvaro. Um minuto de lembrança para Willy Seewald. Jornal União Orgam Republicano. São Leopoldo, n. 279, segunda-feira, 21 de outubro de 1929.

Jornal União Orgam Republicano. São Leopoldo, segunda-feira, 11 de fevereiro de 1929. LAGUNA, Marcelo. Blog Esportes Olímpicos http://esportesolimpicos.ig.com.br/index. php/tag/literatura-esportiva/ terça-feira, 25 de setembro de 2012. 
julho/2017

KILPP, Cecília; ASSMANN, Alice; MAZO, Janice. Turnverein Estrela: ginástica e esportes (1907-1930). Revista Contemporânea - dossiê história \& esporte, ano 4, $\mathrm{n}^{\circ}$ 4, v. 2, p. 1-18, 2014.

MAZO, Janice; GAYA, Adroaldo. As associações desportivas em Porto Alegre, Brasil: espaço de representação da identidade cultural teuto-brasileira. Revista Portuguesa de Ciências do Desporto, vol.6, n. 2, 2006.

MAZO, Janice; MADURO, Paula. A trajetória de um atleta olímpico gaúcho: Willy Seewald, o admirável lançador. In: REPPOLD FILHO, Alberto; PINTO, Leila; RODRIGUES, Rejane; ENGELMAN, Selda (orgs.). Olimpismo e educação Olímpica no Brasil. Porto Alegre: Editora da UFRGS, 2009.

MAZO, Janice; MADURO, Paula; PEREIRA, Ester. A prática do atletismo nas associações desportivas da cidade de Porto Alegre/Rio Grande do Sul nas primeiras décadas do século XX: Primeiros Indícios. Revista Arquivos em Movimentos. Rio de Janeiro, v. 6, n. 2, p. 42-56, 2010.

MAZO, Janice; FROSI, Tiago; MADURO, Paula. O Atleta Olímpico Brasileiro Willy Seewald: memórias do primeiro recordista nacional do lançamento de dardo. Revista Brasileira de Ciências do Esporte, Florianópolis, v. 34, n. 3, p. 537-555, jul./set. 2012. MAZO, Janice \& colaboradores. Associações Esportivas no Rio Grande do Sul: lugares e memórias. Livro Digital. Novo Hamburgo, RS: Editora Feevale, 2012.

MAZO, Janice; SILVA, Carolina; FROSI, Tiago. A Associação Cristã de Moços e a propagação dos esportes em Porto Alegre. Kinesis, v. 30, n. 1, Jan./Jun., 2012.

MAZO, Janice. Olimpíadas, História e Memória: esportistas sul-rio-grandenses nos Jogos Olímpicos (1920 a 1960). In: CONGRESSO BRASILEIRO DE HISTÓRIA DO ESPORTE, LAZER E EDUCAÇÃO FÍSICA, 13, 2014, Londrina. Anais... Londrina: Universidade Estadual de Londrina, v. 13, p. 361-368, 2014.

MAZO, Janice. Catálogo do Esporte e da Educação Física na Revista do Globo. Porto Alegre: PUCRS, 2004.

MIGOTTO, Boca. Documentário O admirável lançador de dardos. Epifania Filmes; Histórias Curtas RBS TV, 2012.

MÜLLER, Telmo. Sociedade Ginástica cem anos de história. São Leopoldo, RS: Rotermund, 1986.

MÜLLER, Norbert. O Olimpismo de Coubertin. IN: Müller, Norbert; TODT, Nelson. Pierre de Coubertin 1863-1937: Olimpismo - Seleção de Textos. EdiPUCRS, 2016.

NICOLINI, Henrique. Jogos Olímpicos de Paris - 1924. Blog Gazeta Esportiva: alem dos fatos. Disponível em: http://blogs.gazetaesportiva.com/henriquenicolini/2015/09/04/ jogos-olimpicos-de-paris-1924/. Acessado em: 15 de junho de 2016.

NORA, Pierre. Entre história e memória: a problemática dos lugares. Revista Projeto História. São Paulo, v. 10, p. 7-28, 1993.

O IMPARCIAL. Supplemento Semanal Illustrado. Rio de Janeiro, 16 de setembro de 1922.

O IMPARCIAL. Supplemento Semanal Illustrado. Anno 3, Num 116. Rio de Janeiro, Sabbado, 8 de setembro de 1928.

PRONI, Marcelo. A reinvenção dos Jogos Olímpicos: um projeto de marketing. Esporte e Sociedade, ano 3, n. 9, 2008. 
PUBLIO, N. Origem da ginástica artística. In: NUNOMURA, M.; NISTAPICCOLO, V. L.

(Org.). Compreendendo a ginástica artística. São Paulo: Phorte, 2005.

RAMOS, Eloísa. O teatro da sociabilidade: os clubes sociais como espaço de representação das elites urbanas alemãs e teuto-brasileiras - São Leopoldo 1858-1930. Tese (Doutorado em História). Universidade Federal do Rio Grande do Sul (UFRGS). Porto Alegre, 2000.

RAMOS, Jayr. Os Exercícios Físicos na História e na Arte: do homem primitivo aos nossos dias. São Paulo: IBRASA, 1982.

RIBEIRO J. R. Guilherme Paraense: O herói esquecido. Revista Magnum, São Leopoldo, ano II, n. 39, jun/jul. 1994.

RUBIO, Katia. Medalhistas olímpicos brasileiros: memórias, histórias e imaginário. São Paulo: Casa do Psicólogo, 2006.

RUBIO, Katia. O atleta e o mito do herói: o imaginário esportivo contemporâneo. São Paulo: Casa do psicólogo, 2001.

SEEWALD TROIAN, Assistência funeral. Disponível em: http://www.funerariast.com.br/ historia/. Acesso em: 03/12/2016.

SEEWALD, Robert. [Carta] 4 jul. 1924, Colônia [para] SEEWALD, Willy. Vila Olímpica. 2 f. Comunicação entre membros da família sobre Jogos Olímpicos de Paris.

SEEWALD, Erich. Erich Luis Seewald (depoimento, 2000). São Leopoldo, RS, 2000.

SEEWALD, Ligia. Ligia Seewald (depoimento, 2001). São Leopoldo, RS.

SEYFERTH, Giralda. Etnicidade e cultura: a constituição da identidade teuto-brasileira. In.:

ZARUR, G. (Org.). Etnia y Nación en América Latina. INTERAMER, n.45, vol.II, 1992.

SEYFERTH, Giralda. A identidade teuto-brasileira numa perspectiva histórica. In: MAUCH,

Cláudia; VASCONCELLOS, N. Os Alemães no sul do Brasil: cultura, etnicidade,

história. Canoas: Ulbra, 1994.

SILVA, Haike. Sogipa: uma trajetória de 130 anos. Publicação comemorativa. Porto Alegre:

Gráfica Editora Pallotti, Editores Associados Ltda., 1997.

SOARES, Carmen. Educação Física: raízes europeias e Brasil. Campinas, SP: Autores Associados, 2002.

SONHO E CONQUISTA: o Brasil nos Jogos Olímpicos do século XX. Comitê Olímpico Brasileiro. Rio de Janeiro: Ouro sobre Azul, 2004.

TEIXEIRA, Maurício; MANARIN, Roger. História do atletismo gaúcho. Portal Atletismo RS.

2003. Disponível em: http://www.atletismors.hpg.com.br, acesso em: 15 jan. 2009.

TESCHE, Leomar. A prática do Turnen entre imigrantes alemães e seus descendentes no RS: 1867-1942. Ijuí, RS: Editora UNIJUÍ, 1996.

TORRES, Cesar. The Latin American "Olympic Explosion" of the 1920s: Causes and Consequences. The International Journal of the History of Sport. Vol. 23, n. 7, 2006. TORRES, César. Jogos Olímpicos Latino-Americanos: Rio de Janeiro 1922. Manaus, AM: Confederação Brasileira de Atletismo, 2012.

TURCO, Benê (org.). Heróis do Atletismo Brasileiro. São Paulo: CBAt, 2016.

VICARI, Paulo; MAZO, Janice. Comemorações do Centenário da Independência do Brasil (1922): Jogos Latino-Americanos no Rio de Janeiro e Jogos Olímpicos no Rio Grande do Sul. Anais do XVII Congresso Brasileiro de Ciências do Esporte, 2011. 
julho/2017

VICARI, Paulo; SILVA, Carolina; MAZO, Janice. Manifestações Esportivas Nas Comemorações do Centenário da Independência do Brasil (1822-1922) no Rio Grande do Sul. Pensar a Prática, v.17, n. 2, 2014, p. 485-502.

VIGARELLO, Georges; HOLT, Richard. O corpo trabalhado - Ginastas e esportistas no século XIX. In CORBIN, Alan; COURTINE, Jean-Jacques; VIGARELLO, Georges (Orgs.). História do Corpo: da revolução à grande guerra. Petrópolis, RJ: Vozes, 2008 (v. 2, p. 445-480).

Recebido em: junho/2016 Aprovado em: dezembro/2016 